\title{
STORED GRAIN PACK FACTOR MEASUREMENTS FOR SOYBEANS, GRAIN SORGHUM, OATS, BARLEY, AND WHEAT
}

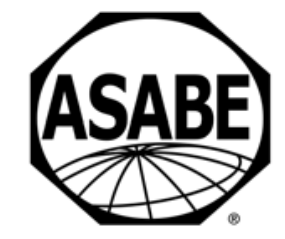

\author{
R. Bhadra, M. E. Casada, A. P. Turner, M. D. Montross, S. A. Thompson, \\ S. G. McNeill, R. G. Maghirang, J. M. Boac
}

\begin{abstract}
Grain and oilseed crops stored in bins undergo compaction due to overbearing pressure of the grain inside the structure. Thus, volume measurements of grain in bins need to be combined with the amount of packing (usually called pack factor) in addition to the initial density so that the mass in the structure can be calculated. Multiple pack factor prediction methods are in use in the grain industry, but they have only been validated in the literature and compared with field data for corn and hard red winter wheat. Predictions from WPACKING, the program in ASABE Standard EP413.2, and two standard USDA methods, the USDA Risk Management Agency (RMA) and USDA Farm Service Agency-Warehouse Licensing and Examination Division (FSA-W) methods, were compared to field measurements of 92 bins containing soybeans, grain sorghum, oats, barley, or soft white or durum wheat. The WPACKING predictions had the lowest absolute average error of predicted mass for soybeans, grain sorghum, barley, and wheat, while the FSA-W method had the lowest error for oats. The RMA method gave the largest prediction errors for all five crops and struggled especially with the low-density, high-compaction crops oats and barley, giving average percent absolute errors near or above $10 \%$ in both cases. Overall, WPACKING, the RMA method, and the FSA-W method had average percent absolute errors of $2.09 \%$, 5.65\%, and 3.62\%, respectively, for the 92 bins. These results can be used to improve pack factor predictions for the grain industry.
\end{abstract}

Keywords. Barley, Grain sorghum, Oats, Pack factor, Soybeans, Steel and concrete bins, Stored grain inventory, Test weight, Wheat.

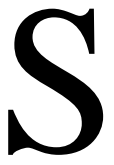

tored grain packing is defined as the increase in grain bulk density caused by the cumulative weight of overbearing material on the compressible grain products. As material is added, the vertical pressure increases in an exponential manner with grain depth, as described by Janssen's equation (Janssen, 1895). Grain packing is influenced by the grain loading method and many parameters of the structure (such as size, shape, and sidewall

Submitted for review in September 2017 as manuscript number PRS 12645; approved for publication by the Processing Systems Community of ASABE in January 2018.

Mention of trade names or commercial products in this article is solely for the purpose of providing specific information and does not imply recommendation or endorsement by the USDA. The USDA is an equal opportunity provider and employer.

The authors are Rumela Bhadra, Engineering Associate, Bureau of Air, Kansas Division of Environment, Topeka, Kansas; Mark E. Casada, Research Agricultural Engineer, USDA-ARS Center for Grain and Animal Health Research, Manhattan, Kansas; Aaron P. Turner, Graduate Student, and Michael D. Montross, Professor and Chair, Department of Biosystems and Agricultural Engineering, University of Kentucky, Lexington, Kentucky; Sidney A. Thompson, Professor, College of Engineering, University of Georgia, Athens, Georgia; Samuel G. McNeill, Associate Extension Professor, Research and Education Center, University of Kentucky, Princeton, Kentucky; Ronaldo G. Maghirang, Professor and Associate Dean, College of Engineering, Kansas State University, Manhattan, Kansas; Josephine M. Boac, Engineering Associate, Bureau of Air, Kansas Division of Environment, Topeka, Kansas. Corresponding author: Mark E. Casada, 1515 College Ave., Manhattan, KS 66502; phone: 785-776-2758; e-mail: casada@ksu.edu. material) and the grain (such as moisture, test weight, friction properties, and depth). The increase in pressure causes an increase in grain bulk density with depth that is accounted for in the differential form of Janssen's equation (Ross et al., 1979). A model, WPACKING, based on this differential form of the equation, predicts the bin storage capacity with the compacted grain and better reflects the physics of the packed grain particles than previous models that assumed the bulk density was constant (Thompson et al., 1987). WPACKING uses uniaxial compressibility curves measured in a laboratory apparatus as a fundamental input to predict packing based on pressures calculated with the differential form of Janssen's equation.

In the grain industry, inventory control and quality management systems, along with crop insurance claims, farm loan programs, and licensed warehouse audits, all require accurate pack factors to determine the mass of grain in storage from bin dimensions and test weights. Multiple methods of determining grain pack factors are in use within the grain industry. The USDA Farm Service Agency's Warehouse Licensing and Examination Division (FSA-W) uses the Federal Warehouse Examiner's Handbook (USDA, n.d.), as do most state warehouse agencies, for measuring commercial grain storage bins for auditing purposes. That handbook gives a procedure for applying a lengthy, empirical table of pack factors to all bin types and sizes found in the U.S. grain industry. For farm bins, the USDA Risk Management Agency (RMA) and the USDA Farm Service Agency's 
County Offices (FSA-C) share briefer empirical pack factor tables (USDA, 2010a, 2010b, 2011a, 2011b), herein called the RMA method, which was originally derived from the FSA-W method. Both the RMA and FSA-W methods take into account test weight during pack factor calculations, but neither method takes into account the changes in packing due to changes in moisture content or changes in density with grain height.

In addition to these two official methods, there are other methods in the literature and in use by grain storage managers in the U.S. (e.g., Malm and Backer, 1985; IAAA, 1980). The computer model developed by Thompson et al. (1987) has become ASABE Standard EP413.2 for estimating the storage capacities of cylindrical grain bins (ASABE, 2010). This model has been validated for corn and hard red winter (HRW) and soft red winter (SRW) wheat (Thompson et al., 1991; Bhadra et al., 2015; Boac et al., 2015) but not for other crops. The objective of this study was to validate WPACKING for barley, oats, grain sorghum, soybeans, and two wheat classes not previously studied (soft white and durum) using grain packing measurements from typical grain storage bins in the U.S. and compare the WPACKING predictions to the RMA and FSA-W methods.

\section{Pack Factor Calculations}

The grain packing that occurs when bulk density increases from the overbearing weight of grain above can be calculated based on the grain bulk density before packing and the bulk density after packing. ASABE Standard EP413.2 (ASABE, 2010) defines the grain compaction factor $\left(f_{c}\right)$ as:

$$
f_{C}=P-1
$$

where $P$ is the ratio of compacted and uncompacted bulk densities, i.e.:

$$
P=\frac{D_{A}}{D_{0}}
$$

where $D_{A}$ is the average bulk density of the grain after packing, $\mathrm{kg} \mathrm{m}^{-3}\left(\mathrm{lb} \mathrm{bu}^{-1}\right.$ ), and $D_{0}$ is the initial bulk density (uncompacted test weight) of the grain from the Winchester bushel test, $\mathrm{kg} \mathrm{m}^{-3}\left(\mathrm{lb} \mathrm{bu}^{-1}\right)$. Both RMA and FSA-W define pack factor as:

$$
R=P\left(\frac{D_{0}}{D_{S}}\right)
$$

where $R$ is the pack factor including test weight, and $D_{S}$ is the standard bulk density (standard test weight) for a given grain type, $\mathrm{kg} \mathrm{m}^{-3}\left(\mathrm{lb} \mathrm{bu}^{-1}\right)$. The mass of grain in the bin, after considering the effect of grain compaction, can be found from the following relationship:

$$
M=D_{S} \cdot R \cdot V
$$

where $M$ is the mass of grain in the bin, $\mathrm{t}(\mathrm{lb})$, and $V$ is the measured volume of grain in the bin, $\mathrm{m}^{3}\left(\mathrm{ft}^{3}\right)$. The bulk density of grain was measured following the Federal Grain In- spection Service (FGIS) handbook for each grain except barley, where initial bulk density of the raw sample was used.

For many grains, including oats, sorghum, and soybeans, the initial bulk density and test weight are identical. For other grains, including wheat and barley, the FGIS procedure requires removing dockage before measuring the test weight, and an initial bulk density measurement of the raw sample including dockage needs to be obtained and used in the calculations for accurate packing calculations. The effect of dockage on the test weight of wheat was presented by Bhadra et al. (2016), where a correlation was developed for calculating the initial density with dockage from the measured test weight without dockage.

\section{MATERIALS AND Methods MEASUREMENTS AND DATA COLLECTION FROM FARM AND ELEVATOR BINS}

The grain packing data were collected from filled grain storage bins on cooperating farms and commercial elevators for soybeans, grain sorghum, oats, barley, soft white wheat, and durum wheat. To obtain a robust data set for model validation, considerable effort was made to measure many different sizes of bins at different locations. All measured bins had been recently loaded with new grain, and the measurements were taken within one month after loading. Bin and grain volume measurements were obtained using a laser distance meter (Disto D8, Leica Geosystems AG, St. Gallen, Switzerland) that has an accuracy of $\pm 1.0 \mathrm{~mm}$ with a tilt sensor accuracy of $\pm 0.1^{\circ}$. The tilt sensor function triggers an error if the laser is tilted beyond $\pm 10^{\circ}$. To avoid tilting and vibrations from handling, we used a tripod pan head mount with independent two-way tilt on a clamp that allowed the laser meter to move in one plane at a time for grain profile measurements. This allowed determination of multiple (normally seven) uniformly spaced points on the grain surface for calculating the angle of repose of the grain. Angle of repose is the cone angle formed when the grain is loaded into silos, a material property that varies with grain type, moisture content, and other factors.

Total grain volume in a bin was calculated as the sum of the conical hopper volume, the top cone volume, and the remaining cylindrical volume, less deductions for any occupied volume such as aeration ducts and augers. The equivalent level height of the bin was determined as the total grain volume divided by the cross-sectional area of the cylindrical bin. Angle of repose is required to calculate the top cone volume in bins. When a spreader is used to level the surface of grain, the angle of repose will be zero or near zero. The laser device was also used to measure the height of grain touching the sidewall of the silos and most other dimensions, with conventional tape measures used occasionally when small dimensions made them more appropriate. Measurable bin dimensions, including diameter, sidewall height, plenum height, roof angle, hopper bottom type and angle, and volume of auger or aeration pipes at the bottom of the bin, were obtained. Bin wall material (concrete or corrugated steel), type of filling (centered or off-centered), and crop properties, 
such as average moisture, test weight, broken corn and foreign material (BCFM), and dockage, were collected from the cooperating grain facility. Mass of grain in the bins was obtained from scale ticket data, which gave the amount of grain loaded in the bin, usually reported in pounds, but occasionally reported in standard bushels. When necessary, reported standard bushels were converted to pounds $\left(48 \mathrm{lb} \mathrm{bu}^{-1}\right.$ for barley, $32 \mathrm{lb} \mathrm{bu}^{-1}$ for oats, $56 \mathrm{lb} \mathrm{bu}^{-1}$ for sorghum, and $60 \mathrm{lb}$ $\mathrm{bu}^{-1}$ for soybeans and wheat). The scale ticket data also included average moisture and test weight for the grain, and additional grade or informational factors such as damage or foreign material in the sample.

\section{APPLICATION OF WPACKING}

The bin and crop measurements were entered into the WPACKING program. The required input data for predicting grain mass are listed below. The WPACKING program input parameters are in English units to be consistent with the U.S. grain industry:

- Crop type

- Average moisture content (\% w.b.)

- Average test weight $\left(\mathrm{lb} \mathrm{bu}^{-1}\right)$

- Dockage level ( $\left.\mathrm{lb} \mathrm{bu}^{-1}\right)$

- Bin diameter, or length of sides if bin is non-circular (ft)

- Grain height at the sidewall (ft)

- Bin wall material (concrete, corrugated steel, smooth steel, or wood)

- Grain cone height (ft) and configuration

- Hopper height (ft)

- Volume deductions (volume of auger, aeration pipes, or other structural elements) $\left(\mathrm{ft}^{3}\right)$.

The accurate pack factor and volume of grain in the bin were calculated by WPACKING based on these inputs. The crop type was selected in WPACKING to match the measured crops in all cases except for durum wheat. Because there is no option for durum wheat in WPACKING, soft wheat was selected for the durum predictions because the kernel shape of soft wheat is more similar to durum than it is to hard wheat, which was the only other wheat option in the program. WPACKING does not include durum wheat because no compressibility data are currently available. After considering the pack factor and volume, the program predicts the mass of grain and compacted test weight along with other bin and grain pile information. The predicted pack factors and predicted total mass in the bins were compared to the predictions from the RMA and FSA-W methods. The RMA and FSA-W methods only have one wheat option, so that general wheat option was selected for all wheat bins for those methods.

\section{RESULTS AND DISCUSSION}

Field data for grain packing were collected from commercial elevators and farms for soybeans, grain sorghum, oats, barley, and soft white and durum wheat. The grain profile and bin dimensions were used with all three methods (WPACKING, RMA, and FSA-W) to predict the pack factor and mass of grain in each bin. The bins measured for each crop, with location, grain quality measurements, and bin parameters for each, are listed in tables 1 through 6. Overall, a wide range of bin sizes and locations was achieved, with bin diameters ranging from 4 to $32 \mathrm{~m}$ for 21 locations. A few bins had very shallow angles of repose (e.g., the soybean bin with an $11.0^{\circ}$ angle), which we identified as apparent angles of repose and did not include in the average angles of repose. After plug flow during unloading of tall and narrow concrete bins, these shallow angles of repose are common. For relatively shallow steel bins, where funnel flow unloading should produce an inverted cone, the cause of shallow angles of repose is not obvious when grain spreaders are not used during loading. Instances of unusually low angles of repose in bins have been reported for HRW wheat in similar bins (Boac et al., 2015).

Relative levels of test weight differed for the different crops, with oats and soybeans often being above and below their standard test weights, respectively, while the other crops were mostly near their standard test weights. The differences between reported mass and predicted mass from the three methods are shown in figures 1 through 5, reported relative to the reported mass using the following equation:

$$
\begin{aligned}
& \text { Percent difference }= \\
& \left\{\left[\left(\text { Predicted Mass }{ }_{W P A C K I N G} \text { or RMA or FSA-W }\right)\right.\right. \\
& -(\text { Reported Mass })] \div(\text { Reported Mass })\} \times 100 \%
\end{aligned}
$$

This percent difference measures the model bias, with positive differences indicating that the method overpredicted compared to the actual mass of the grain in the bin, and negative differences indicating that the method underpredicted. The average of all the individual bin percent differences represents the overall average model bias. In addition, the percent absolute error, which gives the average magnitude of deviations regardless of bias, was calculated as:

$$
\begin{aligned}
& \text { Percent absolute error }= \\
& \mid\left[\left(\text { Predicted Mass }{ }_{W P A C K I N G} \text { or RMA or FSA-W }\right)\right. \\
& -(\text { Reported Mass })] \div(\text { Reported Mass }) \mid \times 100 \%
\end{aligned}
$$

The average of the percent absolute errors for individual bins represents the overall average deviation for the model.

\section{SOYBEAN BINS}

The soybean bins were corrugated steel with flat bottoms. The bin diameters ranged from 4.3 to $22.9 \mathrm{~m}$, and the eave heights varied from 4.3 to $23.7 \mathrm{~m}$ (table 1 ). One soybean bin had an apparent angle of repose of $11.0^{\circ}$, indicating a disturbed surface rather than a true angle of repose. Most of these bins were below the standard test weight for soybeans $\left(772 \mathrm{~kg} \mathrm{~m}^{-3}\right)$. WPACKING predicted average compaction of $0.3 \%$ (pack factor of 1.003), while the RMA and FSA-W methods predicted much greater compactions of $3.1 \%$ and $2.8 \%$, respectively, for soybeans. However, all three methods predicted relatively low values of pack factor because the test weight is included in the pack factor and most of these soybeans were low in test weight. As shown in figure 1, WPACKING had the smallest differences between re- 
Table 1. Bin geometry, crop quality, and pack factors (WPACKING, RMA, and FSA-W methods) for measured bins of soybeans.

\begin{tabular}{|c|c|c|c|c|c|c|c|c|c|c|c|}
\hline \multirow[b]{2}{*}{ Location } & \multirow{2}{*}{$\begin{array}{c}\text { Type of } \\
\text { Bin }\end{array}$} & \multirow{2}{*}{$\begin{array}{c}\text { Test } \\
\text { Weight } \\
\left(\mathrm{kg} \mathrm{m}^{-3}\right)\end{array}$} & \multirow{2}{*}{$\begin{array}{c}\text { Moisture } \\
\text { Content } \\
\text { (\% w.b.) }\end{array}$} & \multirow{2}{*}{$\begin{array}{c}\text { Bin } \\
\text { Diameter } \\
(\mathrm{m})\end{array}$} & \multirow{2}{*}{$\begin{array}{c}\text { Eave } \\
\text { Height } \\
\text { (m) }\end{array}$} & \multirow{2}{*}{$\begin{array}{l}\text { Equivalent } \\
\text { Level } \\
\text { Height }^{\text {[a] }} \\
\text { (m) }\end{array}$} & \multirow{2}{*}{$\begin{array}{c}\text { Angle of } \\
\text { Repose }^{[\mathrm{b}]} \\
\left({ }^{\circ}\right)\end{array}$} & \multirow{2}{*}{$\begin{array}{l}\text { Hopper } \\
\text { Bottom } \\
\text { Angle }^{[c]} \\
\left({ }^{\circ}\right)\end{array}$} & \multicolumn{3}{|c|}{ Pack Factors $^{[\mathrm{d}]}$} \\
\hline & & & & & & & & & WPACKING & RMA & FSA-W \\
\hline \multirow[t]{5}{*}{ Gettysburg, S.D. } & Steel & 740.8 & 11.0 & 18.2 & 6.43 & 6.43 & 23.98 & Flat & 0.991 & 1.051 & 1.022 \\
\hline & Steel & 745.6 & 8.7 & 18.2 & 6.42 & 6.35 & 25.00 & Flat & 0.984 & 1.060 & 1.027 \\
\hline & Steel & 746.8 & 8.5 & 18.2 & 12.42 & 12.42 & 21.81 & Flat & 1.004 & 1.060 & 1.029 \\
\hline & Steel & 749.4 & 9.6 & 12.8 & 6.97 & 6.97 & $11.00^{[\mathrm{e}]}$ & Flat & 1.001 & 1.027 & 1.032 \\
\hline & Steel & 764.2 & 10.5 & 18.2 & 12.24 & 12.23 & 21.20 & Flat & 1.030 & 1.083 & 1.049 \\
\hline Hayfield, Minn. & Steel & 744.1 & 9.8 & 22.9 & 23.70 & 23.70 & 22.00 & Flat & 1.012 & 1.060 & 1.026 \\
\hline \multirow[t]{2}{*}{ Kenyon, Minn. } & Steel & 734.2 & 10.7 & 11.0 & 18.32 & 18.31 & 28.63 & Flat & 0.994 & 1.012 & 1.014 \\
\hline & Steel & 725.7 & 9.5 & 12.9 & 18.07 & 18.14 & 27.14 & Flat & 0.994 & 1.016 & 1.004 \\
\hline \multirow[t]{2}{*}{ Dennison, Minn. } & Steel & 731.4 & 8.4 & 14.4 & 12.99 & 12.99 & 24.15 & Flat & 0.983 & 1.025 & 1.011 \\
\hline & Steel & 744.0 & 8.1 & 14.7 & 13.40 & 13.40 & 25.17 & Flat & 1.000 & 1.040 & 1.026 \\
\hline Severance, Kan. & Steel & 785.4 & 9.5 & 9.5 & 7.55 & 7.55 & 20.67 & Flat & 1.049 & 1.062 & 1.068 \\
\hline \multirow[t]{4}{*}{ Colfax, N.D. } & Steel & 755.6 & 9.3 & 9.8 & 7.90 & 7.90 & 24.66 & Flat & 1.010 & 1.034 & 1.037 \\
\hline & Steel & 742.7 & 8.7 & 7.2 & 8.03 & 8.03 & 24.78 & Flat & 0.984 & 0.994 & 1.013 \\
\hline & Steel & 745.3 & 8.3 & 7.2 & 7.49 & 7.49 & 23.74 & Flat & 0.993 & 1.001 & 1.015 \\
\hline & Steel & 751.7 & 8.9 & 12.0 & 8.53 & 8.53 & 23.00 & Flat & 1.006 & 1.034 & 1.034 \\
\hline \multirow[t]{6}{*}{ Litchville, N.D. } & Steel & 749.1 & 9.5 & 7.3 & 5.58 & 5.58 & 18.17 & Flat & 0.997 & 1.001 & 1.021 \\
\hline & Steel & 749.1 & 9.5 & 7.3 & 5.80 & 5.80 & 21.14 & Flat & 0.998 & 1.001 & 1.021 \\
\hline & Steel & 749.1 & 9.5 & 7.3 & 5.85 & 5.85 & 23.29 & Flat & 0.998 & 1.001 & 1.021 \\
\hline & Steel & 749.1 & 9.5 & 8.5 & 6.03 & 6.03 & 23.85 & Flat & 0.999 & 1.019 & 1.024 \\
\hline & Steel & 778.7 & 9.5 & 7.3 & 6.04 & 6.05 & 28.23 & Flat & 1.039 & 1.037 & 1.053 \\
\hline & Steel & 778.7 & 9.5 & 4.3 & 4.31 & 4.15 & 25.60 & Flat & 0.998 & 1.025 & 1.035 \\
\hline Minimum & & 725.7 & 8.1 & 4.3 & 4.31 & 4.15 & 18.17 & - & 0.983 & 0.994 & 1.004 \\
\hline Maximum & & 778.7 & 11.0 & 22.9 & 23.70 & 23.70 & 28.63 & - & 1.049 & 1.083 & 1.068 \\
\hline Average & & 750.5 & 9.4 & 11.9 & 9.72 & 9.71 & 23.81 & - & 1.003 & 1.031 & 1.028 \\
\hline
\end{tabular}

[a] Equivalent level height is the grain height of the cylinder plus one-third of hopper bottom height plus one-third of cone height.

[b] Apparent angles of repose and flat surfaces are not included in the minimum, maximum, or average values.

[c] Flat bin bottoms are not included in the minimum, maximum, and average hopper bottom angles.

[d] WPACKING pack factors are from Thompson et al. (1987), RMA pack factors are from USDA (2010b), and FSA-W pack factors are from USDA (n.d.). Steel bins are corrugated except as noted.

[e] Apparent angle of repose.

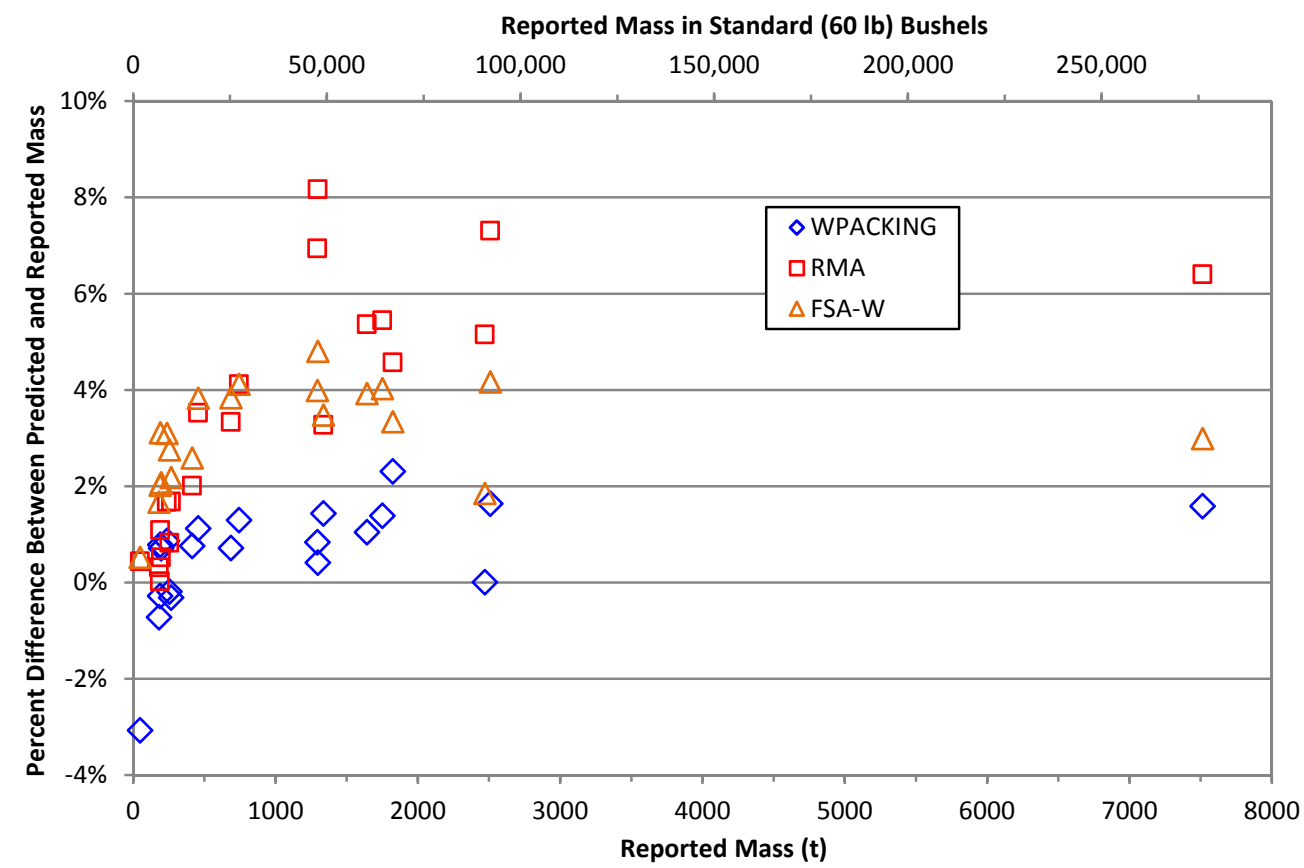

Figure 1. Differences between predicted mass and reported mass using WPACKING, RMA, and FSA-W methods for soybeans (standard bushel $=60 \mathrm{lb})$. All bins are steel.

ported and predicted mass, while the RMA method had the largest differences for large bins (above $1000 \mathrm{t}$ ), and the FSA-W method usually had the largest differences for the bins under $1000 \mathrm{t}$. The median percent differences (table 2) are a measure of overall model bias for each crop. The pack factors predicted by WPACKING produced the smallest median percent differences, and thus the smallest model bias $(+0.79 \%)$, while the RMA and FSA-W methods had much larger median percent differences $(+3.34 \%$ and $+3.11 \%$, respectively). For WPACKING, 19 of 21 prediction errors 
Table 2. Range and median percent differences and average absolute errors for predicted mass compared to reported mass.

\begin{tabular}{|c|c|c|c|c|}
\hline \multirow{2}{*}{$\begin{array}{l}\text { Crop and } \\
\text { Prediction } \\
\text { Method }^{[a]}\end{array}$} & \multicolumn{3}{|c|}{ Percent Difference $^{[b]}$} & \multirow{2}{*}{$\begin{array}{l}\text { Average } \\
\text { Percent } \\
\text { Absolute } \\
\text { Error }^{[c]} \\
\end{array}$} \\
\hline & Minimum & Maximum & Median & \\
\hline \multicolumn{5}{|l|}{ Soybeans } \\
\hline WPACKING & $-3.07 \%$ & $2.31 \%$ & $0.79 \%$ & $1.03 \%$ \\
\hline RMA & $-0.44 \%$ & $8.17 \%$ & $3.34 \%$ & $3.44 \%$ \\
\hline FSA-W & $0.53 \%$ & $4.81 \%$ & $3.11 \%$ & $3.07 \%$ \\
\hline \multicolumn{5}{|l|}{ Sorghum } \\
\hline WPACKING & $-2.34 \%$ & $3.77 \%$ & $-0.30 \%$ & $0.99 \%$ \\
\hline RMA & $-6.55 \%$ & $7.67 \%$ & $0.31 \%$ & $2.95 \%$ \\
\hline FSA-W & $-1.97 \%$ & $5.00 \%$ & $1.87 \%$ & $1.94 \%$ \\
\hline \multicolumn{5}{|l|}{$\overline{\text { Oats }}$} \\
\hline WPACKING & $-8.79 \%$ & $6.45 \%$ & $-2.55 \%$ & $4.17 \%$ \\
\hline RMA & $-16.55 \%$ & $9.39 \%$ & $-9.61 \%$ & $9.29 \%$ \\
\hline FSA-W & $-6.08 \%$ & $4.10 \%$ & $-0.39 \%$ & $2.39 \%$ \\
\hline \multicolumn{5}{|l|}{ Barley } \\
\hline WPACKING & $0.68 \%$ & $6.55 \%$ & $3.53 \%$ & $3.53 \%$ \\
\hline RMA & $-1.76 \%$ & $15.69 \%$ & $13.57 \%$ & $10.92 \%$ \\
\hline FSA-W & $6.20 \%$ & $14.20 \%$ & $12.10 \%$ & $11.47 \%$ \\
\hline \multicolumn{5}{|l|}{ Wheat } \\
\hline WPACKING & $-2.17 \%$ & $-0.26 \%$ & $-0.64 \%$ & $0.81 \%$ \\
\hline RMA & $-3.52 \%$ & $6.62 \%$ & $1.57 \%$ & $2.73 \%$ \\
\hline FSA-W & $-1.80 \%$ & $3.57 \%$ & $2.20 \%$ & $2.32 \%$ \\
\hline \multirow{2}{*}{\multicolumn{5}{|c|}{$\begin{array}{l}\text { Wa] } \\
\text { pack factors are from USDA (2010a, 2010b, 2011a, 2011b), and FSA } \\
\text { W pack factors are from USDA (n.d.). }\end{array}$}} \\
\hline [b] Percent differ & & & & \\
\hline [c] Percent absolt & rors were & lculated us & ; equatio & \\
\hline
\end{tabular}

were between $-1 \%$ and $+2 \%$, with 16 bins out of 21 overpredicted (positive model bias) (fig. 1). Four small bins were underpredicted by between $0 \%$ and $-1 \%$ and a fifth bin, the smallest measured bin (4.3 m diameter, $4.0 \mathrm{~m}$ eave height), had the greatest magnitude of error for soybeans from WPACKING, being underpredicted by $3 \%$.

Bhadra et al. (2015) reported small negative percent differences (underpredictions) by WPACKING for corn with test weights near or above the standard test weight in mostly steel bins, compared to the small positive percent differences (overpredictions) by WPACKING here for soybeans. The RMA and FSA-W methods showed a mixture for corn, with more overpredictions than underpredictions from both methods for corn than for these soybeans. As suggested by the significantly larger median percent difference for the RMA and FSA-W methods in table 2, compared to WPACKING, those two methods had much greater prediction errors in most cases in figure 1 for the 22 corrugated steel soybean bins than did WPACKING. Both the RMA and FSA-W methods were reported to have lower magnitudes of overprediction for corn (median percent differences of $+0.90 \%$ and $+1.45 \%$, respectively) compared to their biases for these soybeans, while WPACKING had slight underpredictions for corn with a $-0.27 \%$ median percent difference. WPACKING had approximately half the average percent absolute error for corn as did the RMA and FSA-W methods for corn ( $0.90 \%$ vs. $1.61 \%$ and $1.86 \%$, respectively) (Bhadra et al., 2015), which was similar to these data for soybeans, but there was an even greater difference between WPACKING and the other two methods for these soybean bins (average percent absolute error of $1.03 \%$ for WPACKING vs. $3.44 \%$ and $3.07 \%$ ). While corn and soybeans are generally similar in packing, some of the differences found here compared to the corn data in the literature may be due to the generally lower than normal test weight values that were observed for the soybeans in this study.

\section{GRAIN SORGHUM BINS}

The majority of grain sorghum bins were concrete, with a mixture of round and interstice shapes, with five large-diameter steel bins also included (table 3 ). The bin diameters ranged from 4.8 to $27.1 \mathrm{~m}$, and the eave heights varied from 6.2 to $29.3 \mathrm{~m}$. The interstice bins were all large cross-sections with equivalent diameters near the diameter of the round bins in the same facility. Two bins with nearly flat surfaces $\left(2.28^{\circ}\right.$ and $\left.4.40^{\circ}\right)$ were measured, indicating that they were disturbed surfaces with apparent rather than true angles of repose. These bins were in the normal range of test weight for sorghum, near or a little above the standard test weight $\left(720 \mathrm{~kg} \mathrm{~m}^{-3}\right)$. For sorghum, WPACKING again had a much lower median percent difference than the RMA method and much lower average percent absolute error than either of the other two methods (table 2). The median percent difference for WPACKING (-0.30\%) was similar in magnitude but opposite in direction as that for the FSA-W method $(+0.31 \%)$. WPACKING consistently predicted the mass of sorghum for the different bin shapes, sizes, and wall materials within $-2 \%$ to $0 \%$ of the reported mass (fig. 2). The FSA$\mathrm{W}$ method consistently predicted mass within $0 \%$ to $+3 \%$ of the reported mass for all bins. The errors in the RMA method differed for different bin wall materials. For the four large corrugated steel bins (the largest sorghum bins in the study, ranging from 5,000 to 9,000 t), the RMA method had large positive percent differences (6\% to $8 \%$ ), while for the 15 concrete bins (all less than 1,000 bu), this method had mostly negative percent differences, one lower than $-6 \%$ and a few positive percent differences of less than $1 \%$.

The RMA method had the largest average percent absolute error of the three methods for sorghum at 2.95\% (table 2). WPACKING had the smallest average percent absolute error of $0.99 \%$, and FSA-W had an average percent absolute error of 1.94\%. Similar data reported by Boac et al. (2015) for HRW wheat in concrete bins showed greater average percent absolute errors for both WPACKING and the FSA-W method (3.75\% and 4.34\%, respectively) than for these sorghum bins, while the RMA method had a slightly higher average absolute error with wheat in concrete bins compared to these sorghum bins (3.25\% vs. 2.95\%). For HRW wheat in corrugated steel bins, WPACKING was reported to have an average absolute error of $1.64 \%$, while the RMA and FSA-W methods had reported average absolute errors of $4.41 \%$ and $3.40 \%$, respectively. The large steel bins of HRW wheat showed a very similar pattern of errors for the three methods, as did these sorghum bins, except the concrete bins had more scatter for HRW wheat than did these sorghum bins. The large scatter for HRW wheat bins was attributed to the difficult geometric shapes of some of the concrete bins in that study (Boac et al., 2015).

\section{OAT BINS}

The oat bins were mostly round concrete, but three concrete interstice bins and three corrugated steel bins were also 
Table 4. Bin geometry, crop quality, and pack factors (WPACKING, RMA, and FSA-W methods) for measured bins of oats.

\begin{tabular}{|c|c|c|c|c|c|c|c|c|c|c|c|}
\hline & Type of & $\begin{array}{c}\text { Test } \\
\text { Weight }\end{array}$ & $\begin{array}{c}\text { Moisture } \\
\text { Content }\end{array}$ & $\begin{array}{c}\text { Bin } \\
\text { Diameter }\end{array}$ & $\begin{array}{l}\text { Eave } \\
\text { Height }\end{array}$ & $\begin{array}{c}\text { Equivalent } \\
\text { Level } \\
\text { Height }^{[a]}\end{array}$ & $\begin{array}{c}\text { Angle of } \\
\text { Repose }\end{array}$ & $\begin{array}{l}\text { Hopper } \\
\text { Bottom } \\
\text { Angle }^{[b]}\end{array}$ & \multicolumn{3}{|c|}{ Pack Factors ${ }^{[c]}$} \\
\hline Location & Bin & $\left(\mathrm{kg} \mathrm{m}^{-3}\right)$ & (\% w.b.) & (m) & & & $\left({ }^{\circ}\right)$ & $\left({ }^{\circ}\right)$ & WPACKING & RMA & FSA-W \\
\hline \multirow[t]{2}{*}{ St. Ansgar, Iowa } & Concrete & 557.7 & 12 & 6.71 & 30.83 & 30.2 & 26.06 & 37.14 & 1.583 & 1.38 & 1.553 \\
\hline & Concrete & 553.1 & 12.5 & 9.30 & 28.95 & 28.09 & 26.56 & 37.90 & 1.588 & 1.398 & 1.632 \\
\hline \multirow[t]{10}{*}{ Sioux City, Neb. } & Concrete & 513.8 & 12.3 & 12.2 & 30.51 & 29.53 & 25.70 & 33.68 & 1.506 & 1.585 & 1.598 \\
\hline & Concrete & 545.2 & 13.0 & 12.2 & 27.97 & 27.04 & 24.62 & 55.18 & 1.579 & 1.651 & 1.663 \\
\hline & Concrete & 529.6 & 12.7 & 12.2 & 29.73 & 28.6 & 29.22 & 46.74 & 1.545 & 1.612 & 1.631 \\
\hline & Concrete & 515.9 & 12.3 & 12.2 & 27.44 & 26.43 & 26.32 & 55.18 & 1.500 & 1.585 & 1.602 \\
\hline & Concrete & 506.2 & 12.4 & 12.2 & 27.86 & 26.73 & 29.28 & 55.56 & 1.480 & 1.572 & 1.581 \\
\hline & Concrete & 538.9 & 12.4 & 7.6 & 22.40 & 21.76 & 26.83 & 57.23 & 1.533 & 1.378 & 1.559 \\
\hline & Concrete & 512.2 & 12.1 & 7.6 & 28.72 & 28.12 & 25.59 & 57.23 & 1.463 & 1.338 & 1.507 \\
\hline & Steel & 537.3 & 12.5 & 27.3 & 16.36 & 14.01 & 27.34 & Flat & 1.554 & 1.832 & 1.647 \\
\hline & Steel & 515.9 & 12.3 & 27.3 & 16.22 & 13.95 & 26.56 & Flat & 1.498 & 1.784 & 1.602 \\
\hline & Steel & 533.3 & 12.6 & 27.3 & 23.48 & 20.92 & 29.44 & Flat & 1.571 & 1.832 & 1.639 \\
\hline \multirow[t]{11}{*}{ St. Ansgar, Iowa } & Concrete & 514.9 & 12.0 & 6.7 & 32.50 & 31.97 & 25.44 & 39.81 & 1.480 & 1.313 & 1.475 \\
\hline & Concrete & 512.0 & 13.2 & 9.3 & 35.31 & 34.6 & 24.65 & 39.81 & 1.497 & 1.338 & 1.550 \\
\hline & Concrete & 555.5 & 11.8 & 6.7 & 33.37 & 32.85 & 24.94 & 39.81 & 1.585 & 1.371 & 1.549 \\
\hline & Concrete & 575.6 & 12.6 & 9.3 & 32.12 & 31.44 & 23.75 & 39.81 & 1.655 & 1.425 & 1.674 \\
\hline & $\begin{array}{l}\text { Concrete } \\
\text { interstice }\end{array}$ & 567.9 & 12.6 & 4.6 & 35.56 & 33.9 & 25.47 & 39.81 & 1.535 & 1.348 & 1.474 \\
\hline & $\begin{array}{l}\text { Concrete } \\
\text { interstice }\end{array}$ & 561.6 & 11.9 & 4.6 & 36.50 & 34.95 & 25.06 & 39.81 & 1.525 & 1.339 & 1.464 \\
\hline & Concrete & 562.2 & 12.7 & 9.3 & 31.49 & 30.8 & 24.13 & 39.81 & 1.621 & 1.407 & 1.649 \\
\hline & Concrete & 572.8 & 12.3 & 6.7 & 35.84 & 35.3 & 25.87 & 39.81 & 1.632 & 1.398 & 1.578 \\
\hline & Concrete & 560.6 & 12.5 & 9.3 & 33.12 & 32.56 & 19.67 & 39.81 & 1.618 & 1.407 & 1.646 \\
\hline & Concrete & 611.4 & 12.7 & 9.3 & 17.51 & 17.51 & 23.94 & 39.81 & 1.787 & 1.477 & 1.737 \\
\hline & $\begin{array}{l}\text { Concrete } \\
\text { interstice }\end{array}$ & 540.6 & 12.3 & 4.6 & 36.50 & 35.12 & 26.10 & 39.81 & 1.482 & 1.313 & 1.431 \\
\hline \multicolumn{2}{|c|}{ Minimum } & 506.2 & 11.8 & 4.6 & 16.22 & 13.95 & 19.67 & 33.68 & 1.463 & 1.313 & 1.431 \\
\hline \multirow{2}{*}{\multicolumn{2}{|c|}{$\begin{array}{l}\text { Maximum } \\
\text { Average }\end{array}$}} & 611.4 & 13.2 & 27.3 & 36.50 & 35.30 & 29.44 & 57.23 & 1.787 & 1.832 & 1.737 \\
\hline & & 543.2 & 12.4 & 11.1 & 29.14 & 28.10 & 25.76 & 43.69 & 1.557 & 1.482 & 1.584 \\
\hline \multirow{2}{*}{\multicolumn{12}{|c|}{ b] Flat bin bottoms are not included in the minimum, maximum, or average hopper bottom angles. }} \\
\hline & & & & & & & & & & & \\
\hline \multicolumn{12}{|c|}{$\begin{array}{l}\text { WPACKING pack factors are from Thompson et al. (1987), RMA pack factors are from USDA (2011b), and FSA-W pack factors are from USDA } \\
\text { (n.d.). Steel bins are corrugated except as noted. }\end{array}$} \\
\hline
\end{tabular}

oats, the relationships between the three methods (fig. 3) had lower predictions for large bins (above 5,000 t) than for were similar to that for sorghum, as shown in figure 2. How- sorghum. For the FSA-W method, that difference resulted in ever, for oats, both the WPACKING and FSA-W methods underpredicting large bins of oats rather than overpredicting

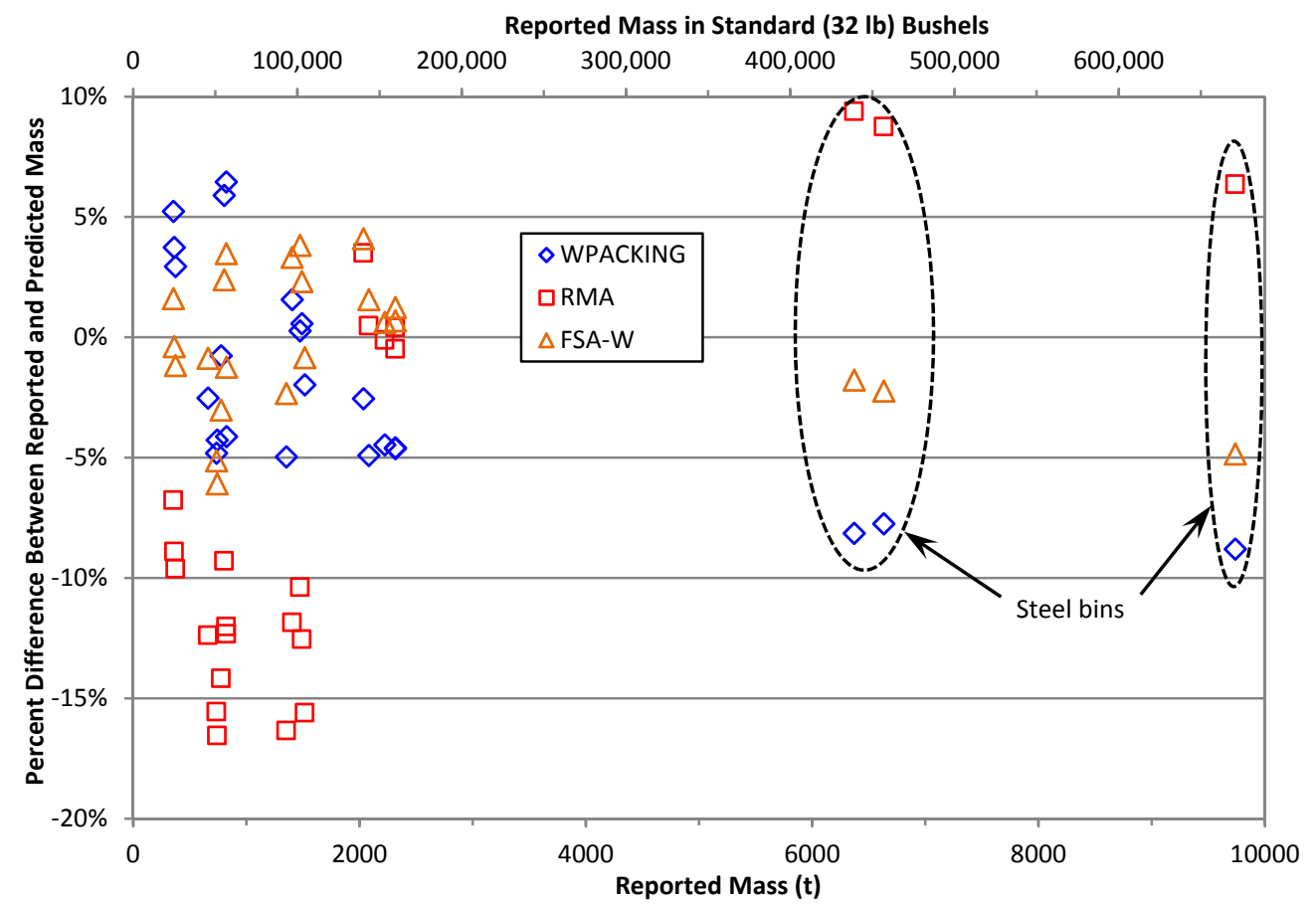

Figure 3. Differences between predicted mass and reported mass using WPACKING, RMA, and FSA-W methods for oats (standard bushel = $32 \mathrm{lb})$. Bins are concrete except as noted. 
large bins, as the method did with sorghum. WPACKING changed from a slight underprediction for large bins of sorghum to underpredicting large bins by $7 \%$ to $9 \%$ for oats. For smaller oat bins (less than 2,500 t), WPACKING and FSA-W exhibited a mixture of overprediction and underprediction. Overall, FSA-W showed a small negative median percent difference of $-0.39 \%$, and WPACKING had a larger negative median percent difference of $-2.55 \%$. This is the only one of the five crops for which WPACKING did not have the smallest magnitude of median percent difference (table 2) and probably reflects the efforts by FSA-W developers to obtain additional data over the years to facilitate better predictions for oats, a crop whose compaction is difficult to predict. The average percent absolute error was $2.39 \%$ for the FSA-W method, $4.17 \%$ for WPACKING, and $9.29 \%$ for the RMA method. The RMA method showed the same problems as with sorghum and overpredicted large bins (6\% to $10 \%$ ) and severely underpredicted small bins (mostly errors of $-8 \%$ to $-17 \%)$. The RMA method for oats had its smallest percent differences ( $0 \%$ to $4 \%$ ) with intermediate-sized bins around 2,000 t (fig. 3).

\section{BARLEY BINS}

The barley bins were mostly corrugated steel but also included three round concrete bins (table 5). The bin equivalent diameters ranged from 6.1 to $32 \mathrm{~m}$, and the eave heights varied from 7.2 to $32 \mathrm{~m}$. These bins were in the normal range of test weight for barley, a little above the standard test weight $\left(618 \mathrm{~kg} \mathrm{~m}^{-3}\right)$. For barley, for both steel and concrete bins, all three methods mostly overpredicted (with two exceptions from the RMA method for small bins) (fig. 4). The RMA and FSA-W methods behaved similarly for intermediate and large bins (from around 2,000 t up to 9,000 t) for barley, which was generally different from the other four crops, for which the RMA method usually overpredicted large bins much more than the FSA-W method. For two out of three smaller bins (less than 2,000 t), the RMA method underpredicted, as it did with small bins of oats and sorghum, although with generally smaller percent differences for these small barley bins. WPACKING exhibited much smaller prediction errors for barley than the other two methods, with an average percent absolute error of $3.53 \%$, compared to $10.9 \%$ for RMA and $11.5 \%$ for FSA-W. The high error for the FSA-W method was unusual and more than double that for the other four crops reported here and for HRW wheat (Boac et al., 2015) and corn (Bhadra et al., 2015). Most of the barley in this study was malting varieties, as were the varieties used in the development of WPACKING. The other two methods do not indicate whether malting or feed varieties were used, but perhaps varietal difference was a factor in the atypically poor predictions from the FSAW method for barley.

Even though barley and oats are the two least dense crops with data available for these three prediction methods (differing from wheat, corn, soybeans, and sorghum in having such low densities), the error patterns in figures 3 and 4 are not similar for these two grains. This is not just a consequence of oats having more concrete bins and barley having more steel bins, as seen by comparing only concrete bins or only steel bins, which also shows little similarity between oats and barley for the three methods. For the RMA and FSA-W methods, with their entirely empirical basis, such difference between crops is expected. We know that the FSA-W developers made extra efforts to obtain more data and refine their prediction of oats, while that extra effort may not have occurred with barley, which is a similarly low-density crop that is comparatively difficult to predict. The WPACKING model uses the same method for all crops but differs in using a compressibility curve specific to each crop. Thus, differences between prediction errors for oats and barley for WPACKING may be largely due to the laboratory compressibility curves for those two crops.

Table 5. Bin geometry, crop quality, and pack factors (WPACKING, RMA, and FSA-W methods) for measured bins of barley.

\begin{tabular}{|c|c|c|c|c|c|c|c|c|c|c|c|}
\hline \multirow[b]{2}{*}{ Location } & \multirow{2}{*}{$\begin{array}{c}\text { Type of } \\
\text { Bin }\end{array}$} & \multirow{2}{*}{$\begin{array}{c}\text { Test } \\
\text { Weight } \\
\left(\mathrm{kg} \mathrm{m}^{-3}\right)\end{array}$} & \multirow{2}{*}{$\begin{array}{c}\text { Moisture } \\
\text { Content } \\
\text { (\% w.b.) }\end{array}$} & \multirow{2}{*}{$\begin{array}{c}\text { Bin } \\
\text { Diameter } \\
\text { (m) }\end{array}$} & \multirow{2}{*}{$\begin{array}{l}\text { Eave } \\
\text { Height } \\
\text { (m) }\end{array}$} & \multirow{2}{*}{$\begin{array}{l}\text { Equivalent } \\
\text { Level } \\
\text { Height }^{\text {[a] }} \\
\text { (m) }\end{array}$} & \multirow{2}{*}{$\begin{array}{c}\text { Angle of } \\
\text { Repose }^{[\mathrm{b}]} \\
\left({ }^{\circ}\right)\end{array}$} & \multirow{2}{*}{$\begin{array}{c}\text { Hopper } \\
\text { Bottom } \\
\text { Angle }^{[\mathrm{c}]} \\
\left({ }^{\circ}\right)\end{array}$} & \multicolumn{3}{|c|}{ Pack Factors $^{[\mathrm{d}]}$} \\
\hline & & & & & & & & & WPACKING & RMA & FSA-W \\
\hline \multirow[t]{2}{*}{ Huntley, Mont. } & Steel & 630.7 & 9.9 & 27.4 & 21.13 & 20.33 & 19.54 & Flat & 1.095 & 1.257 & 1.240 \\
\hline & Steel & 630.7 & 9.9 & 32.0 & 15.32 & 14.92 & 19.72 & Flat & 1.100 & 1.257 & 1.240 \\
\hline \multirow[t]{5}{*}{ Burley, Idaho } & Steel & 662.9 & 9.5 & 27.0 & 21.85 & 21.85 & 22.05 & Flat & 1.192 & 1.307 & 1.290 \\
\hline & Steel & 662.9 & 9.5 & 27.0 & 21.29 & 21.29 & 22.15 & Flat & 1.193 & 1.307 & 1.290 \\
\hline & Steel & 662.9 & 9.5 & 27.0 & 21.84 & 21.84 & 22.64 & Flat & 1.192 & 1.307 & 1.290 \\
\hline & Steel & 662.9 & 9.5 & 27.0 & 21.53 & 21.53 & 21.05 & Flat & 1.191 & 1.307 & 1.290 \\
\hline & Steel & 662.9 & 9.5 & 27.0 & 21.10 & 21.07 & 20.92 & Flat & 1.190 & 1.307 & 1.290 \\
\hline Lewiston, Idaho & Concrete & 643.6 & 10.0 & 8.2 & 31.98 & 31.98 & 23.67 & Flat & 1.172 & 1.12 & 1.224 \\
\hline \multirow[t]{2}{*}{ Moscow, Idaho } & Steel & 669.3 & 10.0 & 23.8 & 7.21 & 7.22 & $4.88^{[\mathrm{e}]}$ & Flat & 1.242 & 1.317 & 1.300 \\
\hline & Steel & 669.3 & 10.0 & 23.8 & 17.47 & 17.47 & 20.48 & Flat & 1.198 & 1.317 & 1.300 \\
\hline \multirow[t]{2}{*}{ Kendrick, Idaho } & Concrete & 662.9 & 10.2 & 6.1 & 14.50 & 14.50 & 15.25 & Flat & 1.174 & 1.124 & 1.215 \\
\hline & Concrete & 662.9 & 10.2 & 6.1 & 15.22 & 15.14 & Flat $^{[\mathrm{f}]}$ & Flat & 1.168 & 1.124 & 1.215 \\
\hline \multicolumn{2}{|c|}{ Minimum } & 657.0 & 9.5 & 6.1 & 7.21 & 7.22 & 15.25 & - & 1.095 & 1.120 & 1.215 \\
\hline \multicolumn{2}{|c|}{ Maximum } & 657.0 & 10.2 & 32.0 & 31.98 & 31.98 & 23.67 & - & 1.242 & 1.317 & 1.300 \\
\hline \multicolumn{2}{|c|}{ Average } & 657.0 & 9.8 & 21.9 & 19.20 & 19.10 & 20.75 & - & 1.176 & 1.254 & 1.265 \\
\hline
\end{tabular}

[a] Equivalent level height is the grain height of the cylinder plus one-third of hopper bottom height plus one-third of cone height.

[b] Apparent angles of repose and flat surfaces are not included in the minimum, maximum, or average values.

[c] Flat bin bottoms are not included in the minimum, maximum, or average hopper bottom angles.

[d] WPACKING pack factors are from Thompson et al. (1987), RMA pack factors are from USDA (2011b), and FSA-W pack factors are from USDA (n.d.). Steel bins are corrugated except as noted.

[e] Apparent angle of repose.

[f] Spreader was used. 


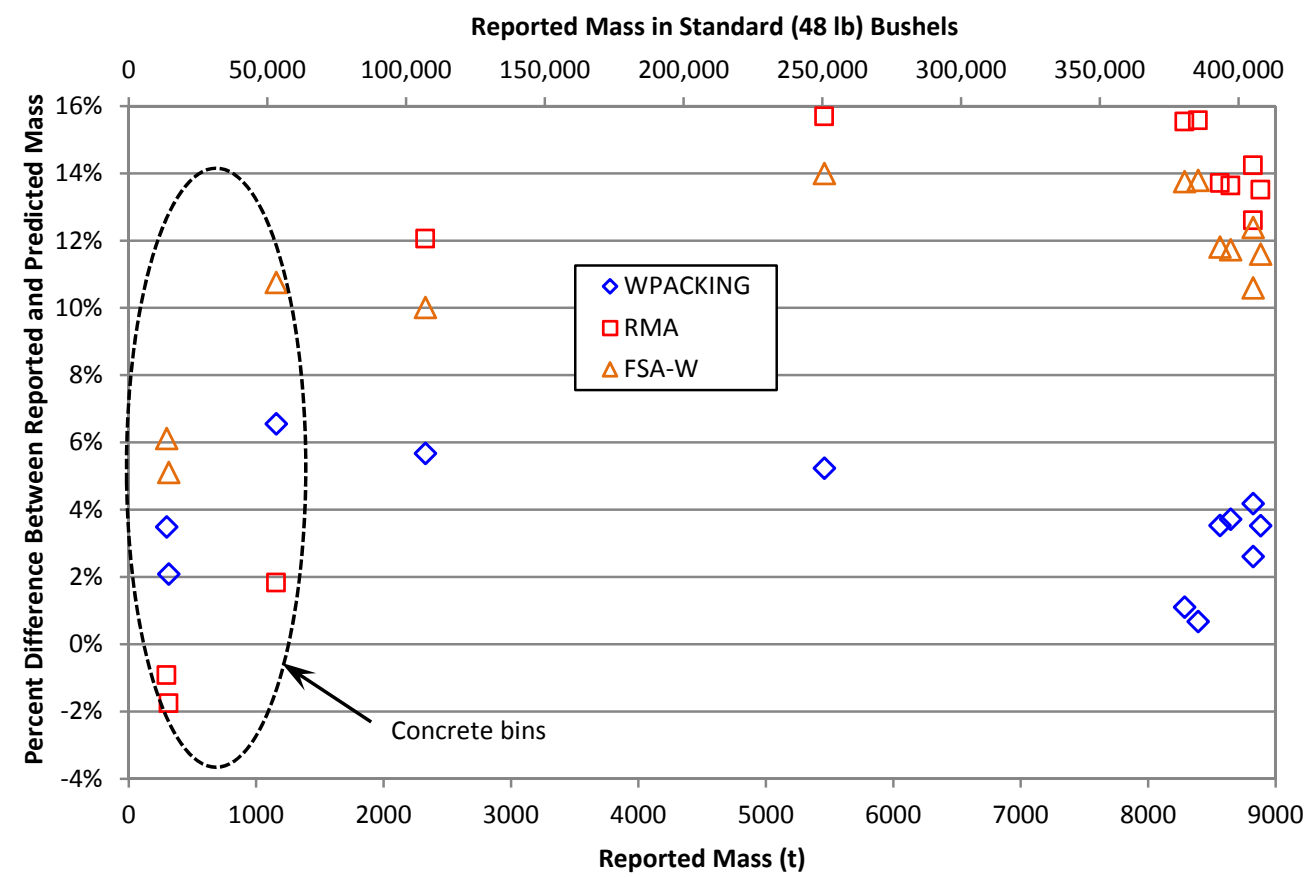

Figure 4. Differences between predicted mass and reported mass using WPACKING, RMA, and FSA-W methods for barley (standard bushel = $48 \mathrm{lb}$ ). Bins are steel except as noted.

\section{WHEAT BINS}

The wheat bins were mostly corrugated or smooth wall steel, with two round concrete bins also measured (table 6). The bin equivalent diameters ranged from 4.0 to $23.8 \mathrm{~m}$, and the eave heights varied from 7.8 to $34.4 \mathrm{~m}$. One wheat bin had an apparent angle of repose of $7.83^{\circ}$, indicating a disturbed surface rather than a true angle of repose. These bins were in the normal range of test weight for wheat, a little above the standard test weight of $772 \mathrm{~kg} \mathrm{~m}^{-3}$. For wheat, the relationships between the three methods (fig. 5) were similar to several other crops, with WPACKING having the smallest differences compared to the reported mass with mostly slight underpredictions. The FSA-W method had small overpredictions with large and intermediate bins and some underpredictions for a few small bins. The RMA method had large overpredictions with large bins, larger underpredictions than the other two methods with small bins, and mostly predicted values in between the other two methods for intermediate bin sizes (500 to $2300 \mathrm{t}$ ).

WPACKING had a median percent difference of $-0.64 \%$ and an average absolute error of $0.81 \%$ for the wheat bins (table 2). The other two methods had positive median percent differences with larger magnitudes of $+1.57 \%$ (RMA) and $+2.20 \%$ (FSA-W). The RMA method had the largest average percent absolute error at $2.73 \%$, while the FSA-W method was slightly lower than the RMA method at 2.32\%. The results for soft white and durum wheat (fig. 5) showed a similar pattern to the results for HRW wheat in steel bins reported by Boac et al. (2015). All three methods had smaller average percent absolute errors for these wheat bins than for the steel HRW wheat bins but had a similar relationship, with the average percent absolute error for WPACKING (1.64\% for HRW wheat) being less than half that of the other two methods (4.41\% and $3.40 \%$ for HRW wheat) and the
RMA method having the largest errors of the three methods. As mentioned in the Materials and Methods section, the soft wheat option was implemented in WPACKING for predicting the pack factor for durum wheat. These predictions were compared to using the hard wheat option in WPACKING (data not shown), and the predictions based on the soft wheat option in WPACKING showed smaller errors than when using the hard wheat option. This was consistent with the similar appearance of durum and soft wheat kernels.

\section{CONCLUSION}

This study reported the first data on the effectiveness of WPACKING, the RMA method, and the FSA-W method for predicting grain packing and mass based on volume measurements for full-sized bins of soybeans, grain sorghum, oats, barley, and soft white and durum wheat. Based on the average percent absolute errors, WPACKING performed better than the other two methods for soybeans, grain sorghum, barley, and wheat (average percent absolute errors of $1.03 \%, 0.83 \%, 3.53 \%$, and $0.81 \%$, respectively), and the FSA-W method performed better for oats (average absolute error of $2.39 \%$ ). This was similar to previous data on wheat in concrete bins and corn in mostly steel bins, for which WPACKING had lower errors than the other two methods. The RMA method had the largest average percent absolute errors for all five of these crops. The RMA method had an average percent absolute error above $9 \%$ for oats, and both the RMA and FSA-W methods had errors above $10 \%$ for barley. Overall, WPACKING, the RMA method, and the FSA-W method had average percent absolute errors of $2.09 \%, 5.65 \%$, and $3.62 \%$, respectively, for these 92 bins. WPACKING is currently under further development and may be adjusted to improve results for all crops. 
Table 6. Bin geometry, crop quality, and pack factors (WPACKING, RMA, and FSA-W methods) for measured bins of wheat.

\begin{tabular}{|c|c|c|c|c|c|c|c|c|c|c|c|c|}
\hline \multirow{2}{*}{\multicolumn{2}{|c|}{$\begin{array}{l}\text { Crop and } \\
\text { Location }\end{array}$}} & \multirow{2}{*}{$\begin{array}{c}\text { Type of } \\
\text { Bin }\end{array}$} & \multirow{2}{*}{$\begin{array}{l}\text { Test } \\
\text { Weight } \\
\left(\mathrm{kg} \mathrm{m}^{-3}\right)\end{array}$} & \multirow{2}{*}{$\begin{array}{l}\text { Moisture } \\
\text { Content } \\
\text { (\% w.b.) }\end{array}$} & \multirow{2}{*}{$\begin{array}{l}\text { Bin } \\
\text { Diameter } \\
(\mathrm{m})\end{array}$} & \multirow{2}{*}{$\begin{array}{l}\text { Eave } \\
\text { Height } \\
(\mathrm{m})\end{array}$} & \multirow{2}{*}{$\begin{array}{l}\text { Equivalent } \\
\text { Level } \\
\text { Height }^{[\mathrm{a}]} \\
\text { (m) }\end{array}$} & \multirow{2}{*}{$\begin{array}{l}\text { Angle of } \\
\text { Repose }^{[b]} \\
\left({ }^{\circ}\right)\end{array}$} & \multirow{2}{*}{$\begin{array}{c}\text { Hopper } \\
\text { Bottom } \\
\text { Angle }^{[\mathrm{c}]} \\
\left(^{\circ}\right)\end{array}$} & \multicolumn{3}{|c|}{ Pack Factors ${ }^{[\mathrm{d}]}$} \\
\hline & & & & & & & & & & WPACKING & RMA & FSA-W \\
\hline \multicolumn{13}{|c|}{ Soft white wheat } \\
\hline \multirow{3}{*}{\multicolumn{2}{|c|}{ Lewiston, Idaho }} & Steel & 804.5 & 9.5 & 16.8 & 34.36 & 22.77 & 18.49 & Flat & 1.111 & 1.180 & 1.138 \\
\hline & & Concrete & 772.3 & 9.5 & 9.2 & 34.09 & 26.16 & 20.79 & 25.0 & 1.063 & 1.065 & 1.090 \\
\hline & & Concrete & 804.5 & 9.5 & 8.2 & 34.33 & 13.59 & Flat $^{[e]}$ & 25.0 & 1.098 & 1.101 & 1.122 \\
\hline & Moscow, Idaho & Steel & 804.5 & 9.0 & 23.8 & 20.21 & 9.29 & 21.97 & Flat & 1.097 & 1.180 & 1.138 \\
\hline \multirow{5}{*}{\multicolumn{2}{|c|}{ Troy, Idaho }} & $\begin{array}{c}\text { Smooth } \\
\text { steel }\end{array}$ & 804.5 & 9.6 & 4.1 & 22.25 & 14.72 & 19.47 & Flat & 1.099 & 1.070 & 1.088 \\
\hline & & $\begin{array}{l}\text { Smooth } \\
\text { steel }\end{array}$ & 799.3 & 9.3 & 4.1 & 22.25 & 15.82 & 20.21 & Flat & 1.093 & 1.063 & 1.082 \\
\hline & & $\begin{array}{c}\text { Smooth } \\
\text { steel }\end{array}$ & 799.3 & 9.3 & 4.0 & 20.12 & 19.88 & 19.53 & Flat & 1.095 & 1.063 & 1.082 \\
\hline & & $\begin{array}{c}\text { Smooth } \\
\text { steel }\end{array}$ & 799.3 & 9.3 & 4.1 & 22.25 & 22.34 & 20.94 & Flat & 1.096 & 1.063 & 1.082 \\
\hline & & $\begin{array}{c}\text { Smooth } \\
\text { steel }\end{array}$ & 799.3 & 9.3 & 11.6 & 19.60 & 9.34 & 20.50 & Flat & 1.090 & 1.126 & 1.132 \\
\hline \multirow{3}{*}{\multicolumn{2}{|c|}{ Kendrick, Idaho }} & $\begin{array}{c}\text { Smooth } \\
\text { steel }\end{array}$ & 813.5 & 9.8 & 11.8 & 24.69 & 18.16 & 18.49 & Flat & 1.120 & 1.141 & 1.149 \\
\hline & & $\begin{array}{c}\text { Smooth } \\
\text { steel }\end{array}$ & 813.5 & 9.8 & 11.8 & 24.69 & 23.66 & 22.84 & Flat & 1.123 & 1.141 & 1.149 \\
\hline & & $\begin{array}{c}\text { Smooth } \\
\text { steel }\end{array}$ & 813.5 & 9.8 & 11.8 & 24.69 & 14.38 & 20.49 & Flat & 1.116 & 1.141 & 1.149 \\
\hline \multicolumn{13}{|c|}{ Durum wheat } \\
\hline \multirow{4}{*}{\multicolumn{2}{|c|}{ Epping, N.D. }} & Steel & 776.0 & 11.9 & 11.0 & 7.78 & 8.38 & 19.62 & Flat & 1.059 & 1.104 & 1.104 \\
\hline & & Steel & 775.4 & 10.2 & 11.0 & 7.78 & 8.22 & 21.25 & Flat & 1.057 & 1.096 & 1.104 \\
\hline & & Steel & 772.9 & 9.6 & 11.0 & 7.78 & 8.52 & 21.94 & Flat & 1.053 & 1.096 & 1.101 \\
\hline & & Steel & 776.3 & 9.8 & 11.0 & 7.78 & 4.02 & $7.83^{[f]}$ & Flat & 1.046 & 1.104 & 1.105 \\
\hline \multicolumn{3}{|c|}{ Minimum } & 772.3 & 9.0 & 4.0 & 7.80 & 4.02 & 18.49 & 25.0 & 1.046 & 1.063 & 1.082 \\
\hline \multicolumn{3}{|c|}{ Maximum } & 813.5 & 11.9 & 23.8 & 34.40 & 26.16 & 22.84 & 25.0 & 1.123 & 1.180 & 1.149 \\
\hline \multicolumn{3}{|c|}{ Average } & 795.5 & 9.7 & 10.3 & 20.93 & 14.95 & 20.47 & 25.0 & 1.089 & 1.108 & 1.113 \\
\hline \multicolumn{13}{|c|}{ [a] Equivalent level height is the grain height of the cylinder plus one-third of hopper bottom height plus one-third of cone height. } \\
\hline \multicolumn{13}{|c|}{ [b] Apparent angles of repose and flat surfaces are not included in the minimum, maximum, or average values. } \\
\hline \multicolumn{13}{|c|}{ [c] Flat bin bottoms are not included in the minimum, maximum, or average hopper bottom angles. } \\
\hline \multirow{2}{*}{\multicolumn{13}{|c|}{$\begin{array}{l}\text { [d] WPACKING pack factors are from Thompson et al. (1987), RMA pack factors are from USDA (2011b), and FSA-W pack factors are from USDA } \\
\text { (n.d.). Steel bins are corrugated except as noted. }\end{array}$}} \\
\hline & & & & & & & & & & & & \\
\hline \multicolumn{13}{|c|}{ Apparent angle of repose. } \\
\hline
\end{tabular}

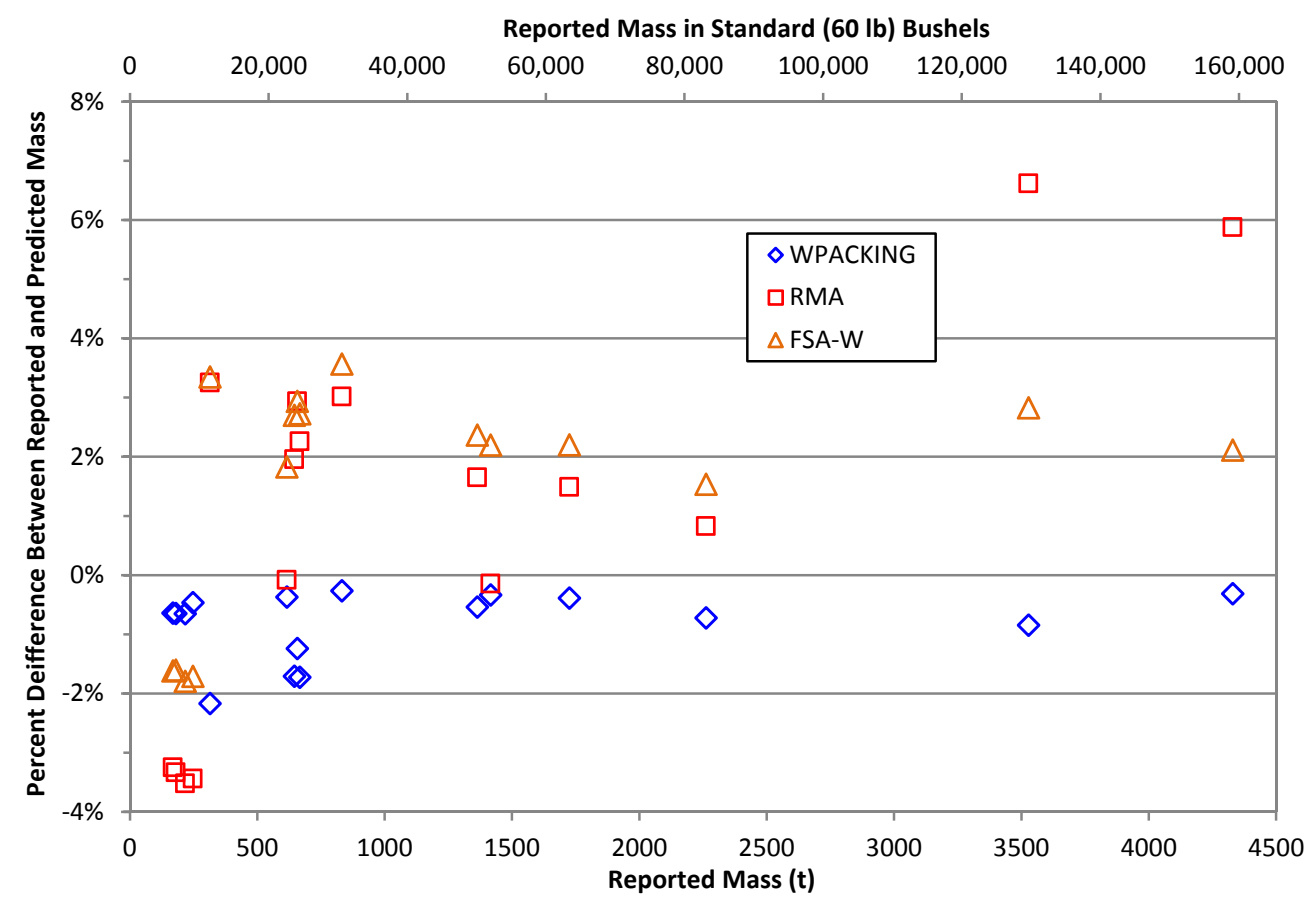

Figure 5. Differences between predicted mass and reported mass using WPACKING, RMA, and FSA-W methods for soft white and durum wheat (standard bushel $=60 \mathrm{lb}$ ). Bins are a mixture of concrete and smooth-wall and corrugated steel. 


\section{ACKNOWLEDGEMENTS}

The research was supported by the USDA (CRIS No. 5430-43440-008-00D) and by the Kansas Agricultural Experiment Station (Contribution No. 18-360-J).

The assistance provided by Dr. Dennis Tilley (USDAARS CGAHR), Kevin Hamm (KSU), Chris Weston (USDA-ARS CGAHR), and Howell Gonzales (KSU) in conducting the field tests is highly appreciated. We want to thank Dalton Henry (Kansas Wheat Commission), Dr. Tom Herald (USDA-ARS CGAHR), Brian Linin and Richard Bauman (Frontier Ag, Inc.), Dr. Danny Rogers, (KSU), Greg Mclure (Riley County Extension Office), Mike Schulte (Oklahoma Wheat Commission), Ben Boerner (Texas Grain \& Feed Association), Ned Bergman and Steve Becker (Farm Service Agency), and Dr. Charles R. Hurburgh Jr. (Iowa State University), and others for assistance in locating cooperators. We also would like to thank our elevator cooperators: Joey Meibergen and Montie Walton (W.B. Johnston Terminal Elevator), Joshua Dechant (Frontier Ag, Inc.); Lindsey Bowers and Steven Craig (United Agricultural Cooperative, Inc.), and Gary Holcomb and Dave Hoffman of (Sunray Coop). Additional thanks are due to Ned Bergman (USDA-FSA Warehouse Licensing and Examination Division, Kansas City Commodity Office) and Tim Oyler (USDA-RMA Product Administration and Standards Division) for providing information on the history and current application of pack factor methods.

\section{REFERENCES}

ASABE. (2010). EP413.2: Procedure for establishing volumetric capacities of cylindrical bins. St. Joseph, MI: ASABE.

Bhadra, R., Casada, M. E., Boac, J. M., Turner, A. P., Thompson, S. A., Montross, M. D., ... McNeill, S. G. (2016). Correlating bulk density (with dockage) and test weight (without dockage) for wheat samples. Appl. Eng. Agric., 32(6), 925-930. https://doi.org/10.13031/aea.32.11692

Bhadra, R., Turner, A. P., Casada, M. E., Montross, M. D., Thompson, S. A., Boac, J. M., ... Maghirang, R. G. (2015). Pack factor measurements for corn in grain storage bins. Trans.
ASABE, 58(3), 879-890. https://doi.org/10.13031/trans.58.11033

Boac, J., Bhadra, R., Casada, M. E., Thompson, S. A., Turner, A. P., Montross, M. D., ... Maghirang, R. G. (2015). Stored grain pack factors for wheat: Comparison of three methods to field measurements. Trans. ASABE, 58(4), 1089-1101.

https://doi.org/10.13031/trans.58.10898

IAAA. (1980). Test pack factor tables. Bloomington: IL: Illinois Agricultural Auditing Association.

Janssen, H. A. (1895). Versuche uber getreidedruck in silozellen. Zeitschrift des Vereines Deutscher Ingenieure, 39(35), 10451049 .

Malm, J. K., \& Backer, L. F. (1985). Compaction factors for six crops. Trans. ASAE, 28(5), 1634-1636. https://doi.org/10.13031/2013.32489

Ross, I. J., Bridges, T. C., Loewer, O. J., \& Walker, J. N. (1979). Grain bin loads as affected by grain moisture content and vertical pressure. Trans. ASAE, 22(3), 592-597. https://doi.org/10.13031/2013.35068

Thompson, S. A., McNeill, S. G., Ross, I. J., \& Bridges, T. C. (1987). Packing factors of whole grains in storage structures. Appl. Eng. Agric., 3(2), 215-221. https://doi.org/10.13031/2013.26677

Thompson, S. A., Schwab, C. V., \& Ross, I. J. (1991). Calibration of a model for packing whole grains. Appl. Eng. Agric., 7(4), 450-456. https://doi.org/10.13031/2013.26244

USDA. (2010a). Grain sorghum loss adjustment handbook. Directive No. 25210. Washington, DC: USDA Risk Management Agency. Retrieved from www.rma.usda.gov/data/25000/2011.html

USDA. (2010b). Soybean loss adjustment standards handbook. Directive No. 25440. Washington, DC: USDA Risk Management Agency. Retrieved from www.rma.usda.gov/data/25000/2011.html

USDA. (2011a). Loss adjustment manual (LAM) standards handbook. Directive No. 25010-1H. Washington, DC: USDA Risk Management Agency. Retrieved from www.rma.usda.gov/data/25000/2012.html

USDA. (2011b). Small grains loss adjustment standards handbook. Directive No. 25430-1H. Washington, DC: USDA Risk Management Agency. Retrieved from www.rma.usda.gov/data/25000/2012.html

USDA. (n.d.). Warehouse examiner's handbook: Grain pack data. WS-3. Washington, DC: USDA Farm Service Agency, Commodity Services, Procurement, and Warehouse Branch. 